\title{
Femtosecond Transient Absorption Studies in Cadmium Selenide Nanocrystal Thin Films Prepared by Chemical Bath Deposition Method
}

\author{
M. C. Rath, J. A. Mondal, D. K. Palit, T. Mukherjee, and H. N. Ghosh \\ Radiation and Photochemistry Division, Bhabha Atomic Research Centre, Trombay, \\ 400085 Mumbai, India
}

Received 30 March 2007; Revised 30 November 2007; Accepted 14 December 2007

Recommended by Tran Kim Anh

\begin{abstract}
Dynamics of photo-excited carrier relaxation processes in cadmium selenide nanocrystal thin films prepared by chemical bath deposition method have been studied by nondegenerate femtosecond transient pump-probe spectroscopy. The carriers were generated by exciting at $400 \mathrm{~nm}$ laser light and monitored by several other wavelengths. The induced absorption followed by a fast bleach recovery observed near and above the bandgap indicates that the photo-excited carriers (electrons) are first trapped by the available traps and then the trapped electrons absorb the probe light to show a delayed absorption process. The transient decay kinetics was found to be multiexponential in nature. The short time constant, $<1$ picosecond, was attributed to the trapping of electrons by the surface and/or deep traps and the long time constant, $\geq 20$ picoseconds, was due to the recombination of the trapped carriers. A very little difference in the relaxation processes was observed in the samples prepared at bath temperatures from $25^{\circ} \mathrm{C}$ to $60^{\circ} \mathrm{C}$.
\end{abstract}

Copyright (c) 2007 M. C. Rath et al. This is an open access article distributed under the Creative Commons Attribution License, which permits unrestricted use, distribution, and reproduction in any medium, provided the original work is properly cited.

\section{INTRODUCTION}

Cadmium selenide (CdSe) nanocrystals (NCs) are important materials for optoelectronics, solar cells, and several biological applications [1-5]. Their optical tunability and stability make them ideal candidate for the future optoelectronics devices such as all optical switches and photovoltaics [6-9]. CdSe NCs are often grown over different substrates in the form of thin films. Several methods are employed for growing these thin films such as chemical deposition (CD) [10 13], electrochemical deposition (ECD) [14], photochemical deposition (PCD) [15], chemical vapour deposition (CVD) $[16,17]$, and molecular beam epitaxy (MBE) [9] methods. Apart from the form of thin films, nanoparticles forms are also prepared and studied in depth [18-20]. The chemical deposition (CD) is the easiest, the cheapest, and the most convenient method, which can produce such materials in a large scale. By changing the deposition parameters, such as concentrations of the individual reagents, bath temperature, and the duration of the deposition time, the NC size and the film thickness can be controlled.
The study of their optical properties is an essential element in the development of above-mentioned devices. Photo-excited carrier relaxation dynamics in these materials have been reported by a number of groups in the recent years. Maly et al. have studied the effect of surface states on the carrier relaxation dynamics in the CdSe NC films in a picosecond time-scale resolution [21]. Simurda et al. have reported the effect of surface passivation by ammonia in the carrier relaxation dynamics in the CdSe NC thin films [22]. Ai et al. have studied charge carrier dynamics in CdSe NC films using a femtosecond degenerate pump-probe technique [23]. Several other groups have reported the carrier dynamics in CdSe quantum structures in various conditions [24-29]. However, the carrier relaxation dynamics in the CdSe NC films prepared by the CD method are still to be investigated in a thoroughly manner. In this study, we report the carrier relaxation dynamics in CdSe NC films prepared by the CD method at different temperatures by femtosecond transient nonresonant nondegenerate pump-probe spectroscopy. We probed the carrier relaxation processes at various probe wavelengths by exciting at photon energy of $3.1 \mathrm{eV}(400 \mathrm{~nm})$. 


\section{EXPERIMENTAL}

\subsection{Sample preparation}

CdSe NC films were grown on clean glass substrates by the chemical deposition (CD) method [10-13]. Briefly, $10 \mathrm{~mL}$ $0.5 \mathrm{~mol} \mathrm{dm}^{-3} \mathrm{CdSO}_{4}$ solution was taken in a $40 \mathrm{~mL}$ beaker. Ammonia solution was added slowly with a constant stirring until the solution became clearly transparent. A freshly prepared $10 \mathrm{~mL} \mathrm{Na} \mathrm{SeSO}_{3}$ solution was added slowly to it. Clean glass slides were inserted into the beaker and inclined at about $20^{\circ}$ angles to its wall. The bath temperature was kept at four different temperatures: $25^{\circ} \mathrm{C}, 40^{\circ} \mathrm{C}, 50^{\circ} \mathrm{C}$, and $60^{\circ} \mathrm{C}$. The deposition was carried out for 30 minutes to 3 hours depending on the bath temperatures. One side of the slide was cleaned by a cotton plug dipped in a dilute $\mathrm{HCl}$. The films were air-dried and stored for further study. The orange-coloured as-grown films were characterized by XRD, SEM, EDAX, and optical absorption spectroscopy. The samples were characterized by atomic force microscope (AFM) at ambient conditions.

\subsection{Femtosecond transient absorption spectrometer}

Ultrafast carrier relaxation dynamics study was performed by using a multipass amplified femtosecond Ti:sapphire laser system from Avesta, Russia ( $1 \mathrm{kHz}$ repetition rate at $800 \mathrm{~nm}$, 50 femtoseconds, $800 \mu \mathrm{J} /$ pulse). The details of the setup are described elsewhere [30]. Typically, the $800 \mathrm{~nm}$ output pulses from the multipass amplifier are split into two parts to generate pump and probe pulses. One part, with $200 \mu \mathrm{J} /$ pulse, is frequency doubled in a $\mathrm{BBO}$ crystal to generate pump pulse at $400 \mathrm{~nm}$. The other part is focused onto a $1.5 \mathrm{~mm}$ thick sapphire window to generate a white-light continuum for the probe pulses $(470 \mathrm{~nm}$ to $1000 \mathrm{~nm})$. The pump and probe energies at the sample position were $18 \mu \mathrm{J} /$ pulse and $200 \mathrm{~nJ} /$ pulse, respectively. The angle between the pump and probe pulses is about $8^{\circ}$. The pump pulses are set at magic angle $\left(54.7^{\circ}\right)$ with respect to the probe pulses, which are horizontally polarised. The pump and probe spot sizes at the sample position were about $400 \mu \mathrm{m}$ and $200 \mu \mathrm{m}$, respectively. The pump-probe setup works in transmission mode. The wavelength of the white light (probe pulses) was tuned by the interference filter just before the photodiodes. The signal collected by the photodiodes is fed to the boxcar, and the data acquisition is done by using the Labview programme in a picosecond. The typical noise in the measured absorbance change is less than about $0.4 \%$.

\section{RESULTS AND DISCUSSION}

The optical absorption spectra (Figure 1) of the films exhibited distinct excitonic absorption peaks $\left(E_{1}\right)$ at around $540 \mathrm{~nm}(2.29 \mathrm{eV}), 550 \mathrm{~nm}(2.25 \mathrm{eV}), 562 \mathrm{~nm}(2.21 \mathrm{eV})$, and $574 \mathrm{~nm}(2.16 \mathrm{eV})$ for the $25^{\circ} \mathrm{C}, 40^{\circ} \mathrm{C}, 50^{\circ} \mathrm{C}$, and $60^{\circ} \mathrm{C}$ samples, respectively. The optical absorption spectra extend beyond $700 \mathrm{~nm}$. The extended absorption beyond $700 \mathrm{~nm}$ that arises in the chemical method of preparation can be attributed to the surface states. The absorption peak corresponds to the lowest allowed transition $1 S_{e}-1 S_{h}$ [27, 31-33].
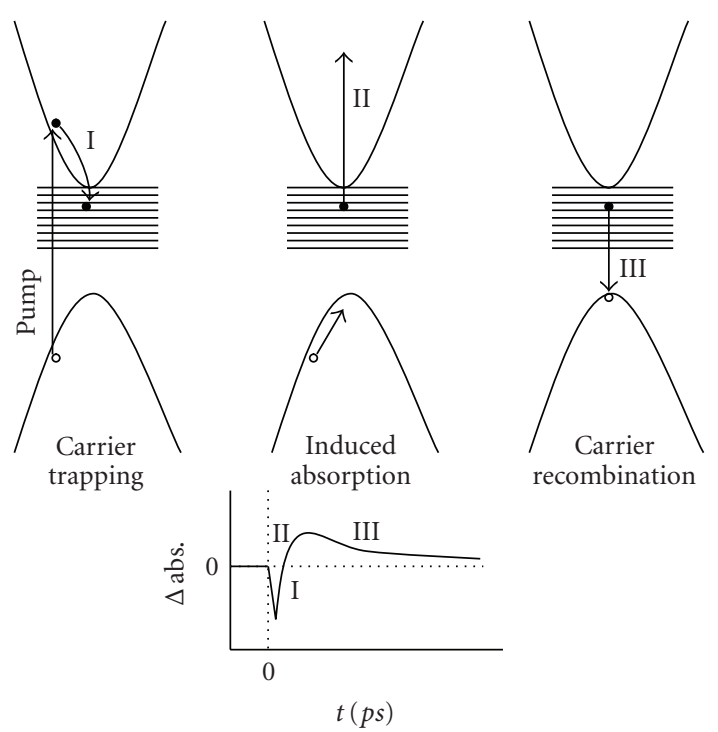

Scheme 1: Schematic representation of the photo-excited carrier relaxation processes in the CdSe NC thin films prepared by the CD method. I: carrier trapping process; II: induced absorption process; III: recombination of the trapped carriers. All the three processes occur consecutively and the resultant transient absorption signal for a bandgap probe would look like a model picture as shown at the bottom.

There is a systematic shift in the excitonic absorption peak towards the higher-wavelength side with the increase in the reaction of bath temperature. This indicates that there is an increase in the grain size of the nanocrystals with temperature. The room temperature bandgap of the bulk CdSe is $1.74 \mathrm{eV}$. The NC grain size was determined from the energy of quantum confinement (i.e., $\Delta E=E_{1}-E_{g}$ ) using modified Brus equation, which ranges from $1.9 \mathrm{~nm}$ to $2.5 \mathrm{~nm}$ for the $25^{\circ} \mathrm{C}$ to $60^{\circ} \mathrm{C}$ samples, respectively. This indicates that the $\mathrm{NC}$ consists of quantum size particles (de Broglie wavelength of the charge carriers $=4.8 \mathrm{~nm}$ at room temperature).

The grain sizes of the NC films were also calculated from the XRD data using Scherrer's formula and listed in Table 1. The slight deviation in the grain size obtained from two different results could be due to a broad nature of the absorption spectra. The AFM picture of one of the CdSe samples prepared at $40^{\circ} \mathrm{C}$ is shown in Figure 2. The picture indicates a nice uniform growth of the nanocrystals of CdSe over the glass substrates. The formation of CdSe nanocrystals prepared by the chemical bath deposition method has been reported by Kale et al. [34] where they have observed a direct evidence of the formation of CdSe nanocrystals from the AFM and SEM data. The thickness of the samples determined from the weight difference method was found to be between 300 and $500 \mathrm{~nm}$. The thickness of the samples as determined from the AFM measurements fairly matches with the previous ones.

The emission from these samples was too weak to be detected by normal steady-state fluorescence spectrometer at room temperature; however, a very week emission could be observed only at higher wavelengths $>600 \mathrm{~nm}$ for all 


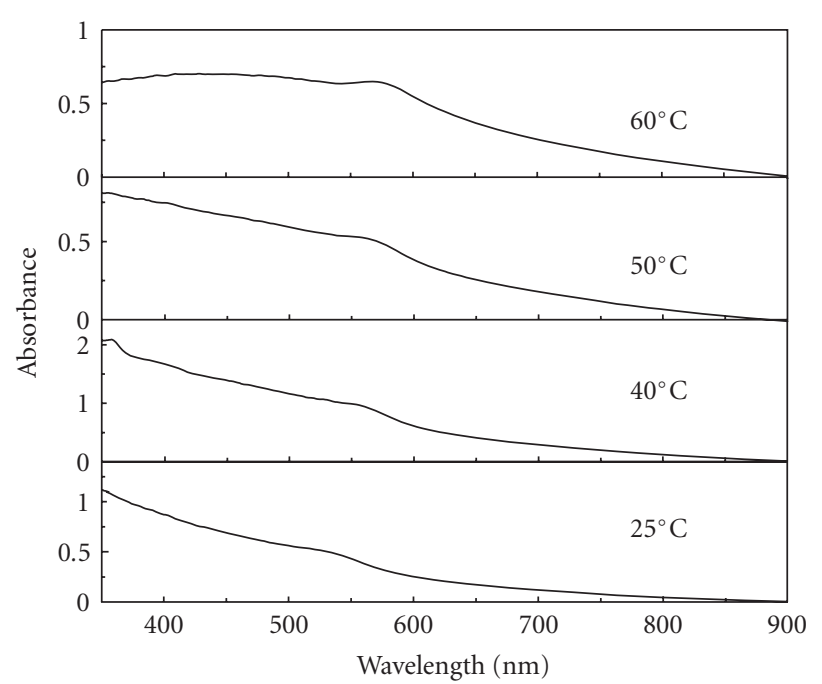

FIGURE 1: The room temperature optical absorption spectra of four different CdSe NC thin films.

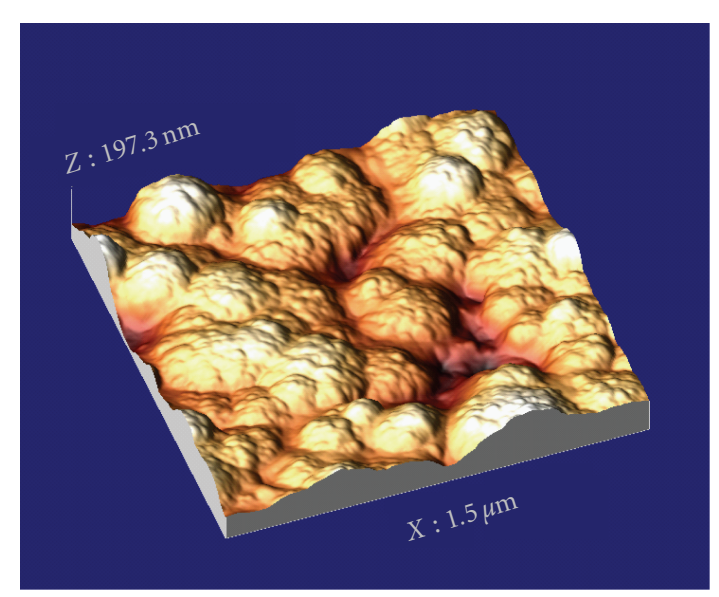

FIgURE 2: A 3-dimensional AFM picture of CdSe NC thin film sample prepared at $40^{\circ} \mathrm{C}$.

the samples. This could be due to the predominance of a nonradiative deactivation of photo-excited carriers via the trap states available in these samples. The pump-probe experiments have been carried out at room temperature. The samples were excited (pumped) by a $400 \mathrm{~nm}(3.1 \mathrm{eV})$ light and probed at various other wavelengths, such as $470 \mathrm{~nm}$ $(2.64 \mathrm{eV}), 610 \mathrm{~nm}(2.03 \mathrm{eV}), 710 \mathrm{~nm}(1.75 \mathrm{eV})$, and $900 \mathrm{~nm}$ $(1.38 \mathrm{eV})$. The $470 \mathrm{~nm}$ probe light corresponds to an energy higher than the $1 S_{e}-1 S_{h}$ transition level, $610 \mathrm{~nm}$ corresponds very close to the $1 S_{e}-1 S_{h}$ transition, $710 \mathrm{~nm}$ corresponds to just below the $1 S_{e}-1 S_{h}$ transition, and $900 \mathrm{~nm}$ corresponds to very less than the bandgap transition in these materials.

Time-resolved transient absorption spectra of a CdSe NC film grown at $40^{\circ} \mathrm{C}$ obtained from the pump-probe spectroscopy are shown in Figure 3. A bleach signal was observed in this sample from $470 \mathrm{~nm}$ to about $800 \mathrm{~nm}$ with a peak at

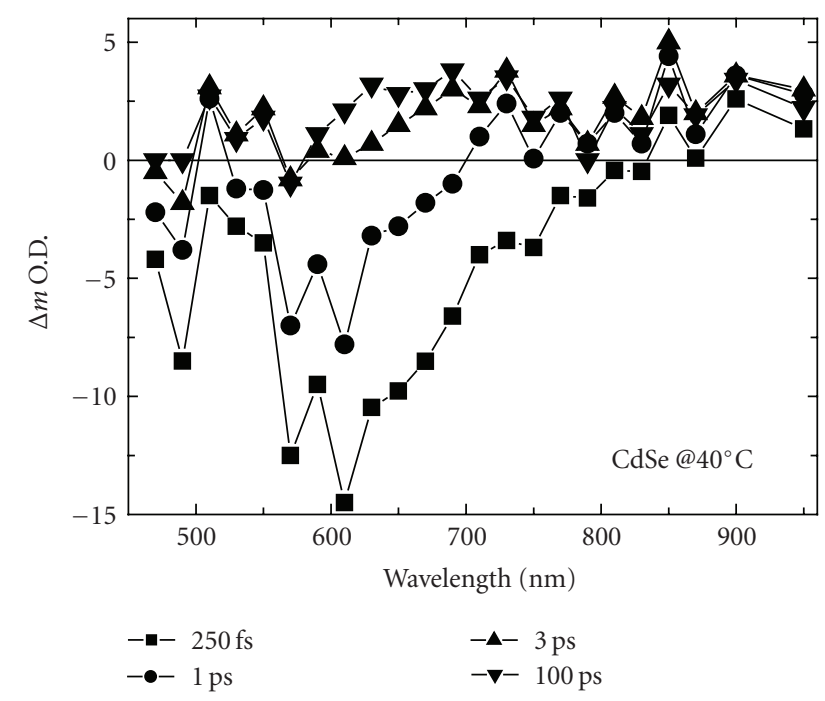

FIGURE 3: The time-resolved transient absorption spectra of CdSe $\mathrm{NC}$ thin film prepared at $40^{\circ} \mathrm{C}$.

around $610 \mathrm{~nm}$. This recovers within a short time about $\leq 3$ picoseconds with the formation of an induced absorption in the entire visible range. One set of the pump-probe kinetic profiles obtained at different probe wavelengths for the sample grown at $25^{\circ} \mathrm{C}$ is shown in Figure 4. The kinetic profiles for all the four samples monitored at two probe wavelengths $610 \mathrm{~nm}$ and $900 \mathrm{~nm}$ are shown in Figures 5 and 6, respectively. The kinetic profiles for the other three samples grown at $40^{\circ} \mathrm{C}, 50^{\circ} \mathrm{C}$, and $60^{\circ} \mathrm{C}$ can be found in the supporting information. The inset in the figures shows in a short-time scale. The slight deviations in the kinetic profiles could be related to their transient absorption spectral patterns. There was no change in the kinetic profiles with the reduction in the pump energy from $18 \mu \mathrm{J} /$ pulse to $8 \mu \mathrm{J} /$ pulse except that there was a reduction in the signal intensity. The kinetic profiles at various probe wavelengths were fitted with multiexponential fitting parameters by using the Labview fitting programme, and the best-fit results are listed in Table 1.

In this case, the pump pulses photo-excite the valence band (VB) electrons to the conduction band (CB) creating a hot electron density in the $\mathrm{CB}$ and holes in the VB. The probe pulses monitor these photo-excited electrons in the $\mathrm{CB}$ by a band-to-band absorption process. However, it is true that on photo-excitation, charge carriers are generated which is due to hole in the valence band and electron in the conduction band. So it is quite obvious to think that both the electron and the hole can have transient absorption in the visible region. However, the charge carriers can have different cross-section of transient absorption in different probing regions. Burda et al. [35] carried out ultrafast transient spectroscopy on CdSe nanoparticles monitoring at visible, near IR, and mid-IR regions separately. They have shown clearly that cross-section of electron is more in the visible and midIR regions, and on the other hand, the hole has more crosssection in the near-IR region. They have observed that excited dynamics in the visible and mid-IR regions are solely 
TABLE 1: Photo-excited electron decays time constants in different CdSe NC thin films probing at different wavelengths. (br: bleach recovery; ia: induced absorption; iad: induced absorption decay; af: absorption formation; ad: absorption decay. The bracket values indicate the relative percentage calculated from their pre-exponential factor values obtained from the best-fit data. The negative percentage values in the bracket indicate the time constants for the decay processes, and the total relative percentage values for a given set of data are normalized to 100.)

\begin{tabular}{|c|c|c|c|c|c|}
\hline \multirow{2}{*}{ Bath temp. $\left( \pm 2^{\circ} \mathrm{C}\right)$} & \multicolumn{4}{|c|}{ Time constants in picoseconds (relative percentage) } & \multirow{2}{*}{ Grain size, a (nm) } \\
\hline & $470 \mathrm{~nm}$ & $610 \mathrm{~nm}$ & $710 \mathrm{~nm}$ & $900 \mathrm{~nm}$ & \\
\hline \multirow{3}{*}{25} & $0.5(73 \%)$ br & 0.65 af & 0.25 af & $1.5(62 \%)$ ad & \multirow{3}{*}{$2.9 \pm 0.3$} \\
\hline & $2.0(35 \%)$ ia & $10(52 \%)$ ad & $10(47 \%)$ ad & $20(20 \%)$ ad & \\
\hline & $>100(-8 \%)$ iad & $>100(48 \%)$ ad & $>100(53 \%)$ ad & $>100(18 \%)$ ad & \\
\hline \multirow{4}{*}{40} & 03 (850) br & $03(770 \%) \mathrm{br}$ & $0.3(94 \%)$ br & 2 af & \multirow{4}{*}{$3.2 \pm 0.3$} \\
\hline & $0.3(05 \%)$ Or & $0.3(1 / \%)$ DI & $3(77 \%)$ ia & $20(73 \%)$ ad & \\
\hline & $3.5(10 \%)$ br & $2.5(33 \%)$ ia & $6(-51 \%)$ iad & $>100(27 \%)$ ad & \\
\hline & $>100(5 \%)$ br & $>100(-10 \%)$ iad & $>100(-20 \%)$ iad & & \\
\hline \multirow{4}{*}{50} & $0.6(112 \%) \mathrm{br}$ & $0.65(88 \%) \mathrm{br}$ & $0.23(98 \%)$ br & 2 af & \multirow{4}{*}{$3.6 \pm 0.4$} \\
\hline & & & $2.5(16 \%)$ ia & $5(14 \%)$ ad & \\
\hline & - & $3(28 \%)$ ia & $20(-10 \%) \mathrm{iad}$ & $50(5 \%) \mathrm{ad}$ & \\
\hline & $3(-13 \%) \mathrm{iad}$ & $>100(-16 \%) \mathrm{iad}$ & $>100(-4 \%)$ iad & $>100(81 \%)$ ad & \\
\hline \multirow{4}{*}{60} & $0.5(103 \%)$ br & $0.35(140 \%)$ br & - & - & \multirow{4}{*}{$3.8 \pm 0.4$} \\
\hline & $6(33 \%)$ ia & $1(8 \%)$ ia & - & - & \\
\hline & $10(-30 \%) \mathrm{iad}$ & $20(-30 \%)$ iad & $3(44 \%) \mathrm{ad}$ & $1(77 \%)$ ad & \\
\hline & $>100(-6 \%) \mathrm{iad}$ & $>100(-18 \%)$ iad & $>100(56 \%)$ ad & $20(23 \%) \mathrm{ad}$ & \\
\hline
\end{tabular}

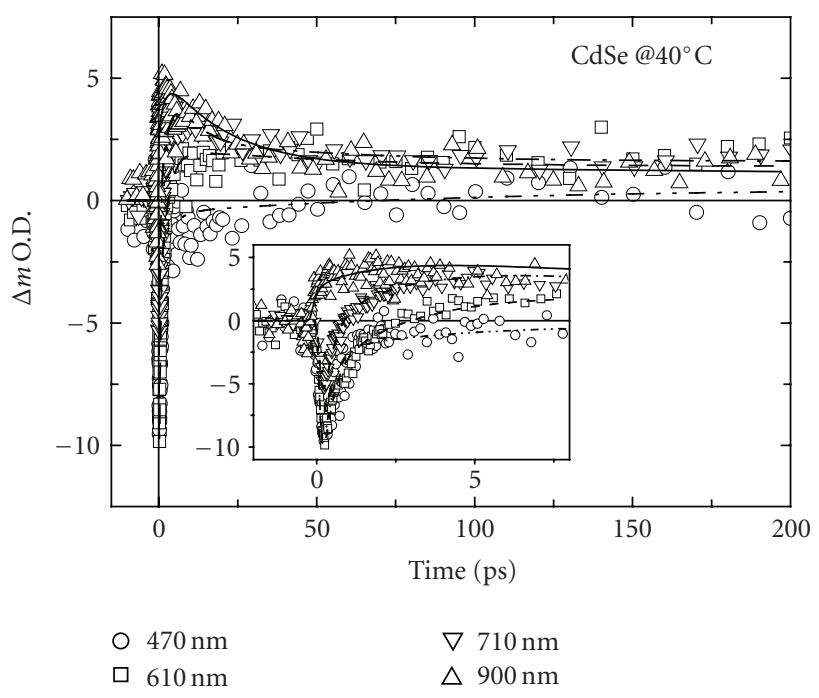

FIGURE 4: Kinetic profiles obtained at different probe wavelengths in the pump-probe experiment for the CdSe NC thin film samples prepared at $40^{\circ} \mathrm{C}$. Inset: kinetic profiles at short-time scales. The solid lines represent the best-fit curves.

due to electron in the conduction band; on the other hand, transient absorption in the near-IR region is due to the hole in the valence band. In the present investigation, we are monitoring the charge carriers in the visible region (470-950 nm) which are attributing to the relaxation dynamics due to electron. However, there might be a very little contribution due to the hole absorption in the visible region which is negligible. Now, the kinetic bleach signals obtained at the probe wavelengths other than $900 \mathrm{~nm}$ are found to be associated

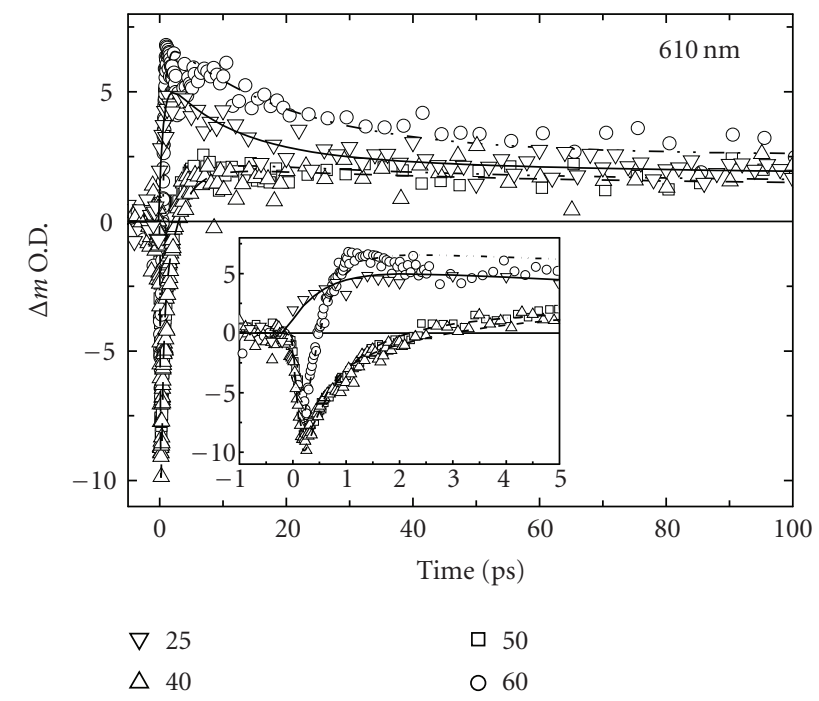

FIgURE 5: Kinetic profiles obtained at $610 \mathrm{~nm}$ in the pump-probe experiment for the CdSe NC thin film samples prepared at $25^{\circ} \mathrm{C}$, $40^{\circ} \mathrm{C}, 50^{\circ} \mathrm{C}$, and $60^{\circ} \mathrm{C}$. Inset: kinetic profiles at short-time scales. The solid lines represent the best-fit curves.

with the formation of an induced absorption process, which decays at a long-time scale. The pulse-width-limited rise time in the bleach signal indicates that the carriers relax down to a lower-energy level of the conduction band during this time period (i.e., about 100 femtoseconds). The overall excitation and de-excitation pathways for these samples are represented in Scheme 1. The pump-probe experiments monitor the photo-excited electrons in the $\mathrm{CB}$, as the bandgap absorption is mainly dependent on the $\mathrm{CB}$ electron density. 


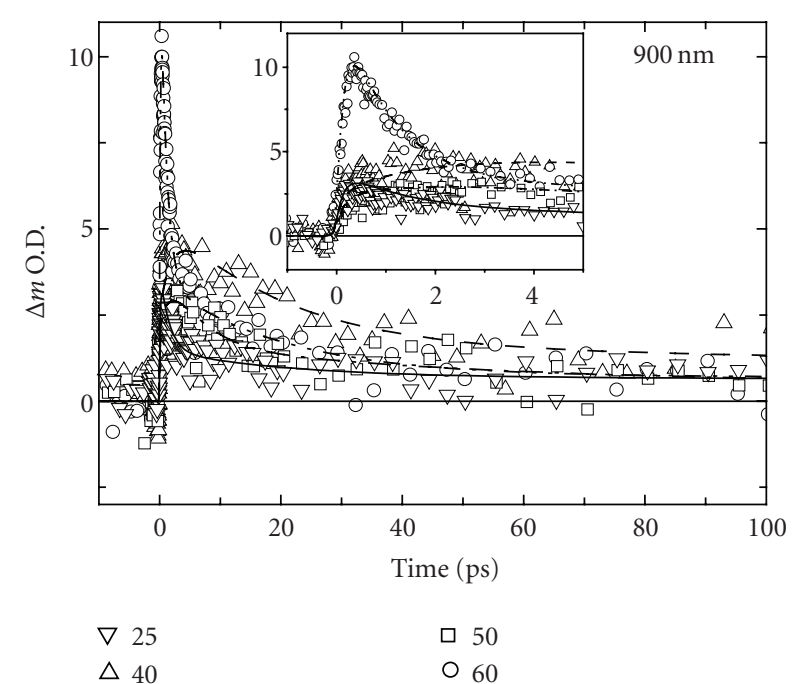

FIGURE 6: Kinetic profiles obtained at $900 \mathrm{~nm}$ in the pump-probe experiment for the CdSe $\mathrm{NC}$ thin film samples prepared at $25^{\circ} \mathrm{C}$, $40^{\circ} \mathrm{C}, 50^{\circ} \mathrm{C}$, and $60^{\circ} \mathrm{C}$. Inset: kinetic profiles at short-time scales. The solid lines represent the best-fit curves.

The pump-probe kinetic profiles obtained at the bandgap probe wavelengths can be modeled to an empirical equation as written below:

$$
-d \alpha / d t=k_{1} n-k_{2}(n+m)+k_{3} n
$$

where $k_{1}, k_{2}$, and $k_{3}$ are the rate constants for the three processes such as carrier trapping, induced absorption, and carrier recombination, as indicated in Scheme 1. In (1), $n$ is the number density of the photo-excited electrons at the conduction band (CB), $m$ is the inherent free-electron density available at the trap centers, and $\alpha$ is the overall probe absorption in the materials. A model kinetic profile is shown the bottom of Scheme 1. The initial bleach signal is due to the band filling effect for the bandgap probe wavelengths. A bleach signal is not expected for the probe wavelength $900 \mathrm{~nm}$. The time constants for the bleach recovery and the formation of an induced absorption process are found to be less than 1 picosecond and slightly higher than 2 picoseconds, respectively. The fast time constant $(<1$ picosecond $)$ is due to the trapping of the electrons at the surface traps and/or deep traps. The second component ( $>2$ picoseconds) is due to the absorption of the trapped electrons at the trap centers as represented in Scheme 1 . The relative percentages of the observed time constants were calculated from the pre-exponential factors, and the overall percentage was fixed at 100 . The relative percentage of the first time constant is found to be always higher than that of the second one. Therefore, the trapping of the electrons and the formation of the absorbing trapped electrons for the further absorption to a higher energy state in the $\mathrm{CB}$ are very much comprehensive to each other. The long decay time constants obtained at these probe wavelengths indicate a slow recombination process of the trapped carriers. Similar slow recombination dynamics has been observed by Benjamin et al. [36] in GaAs semiconductor materials, which have attributed to the recombination dynamics due to midgap trap states. The amplitude of the bleach signal was higher than that of the induced absorption, and the residual part of the absorption decay signal is very less as compared to the previous two. Therefore, the samples could be classified as one of the fast optical response materials. There was a slight difference in the time constants obtained in the four different samples. However, the observed time constants follow a systematic pattern following the model given in Scheme 1. The carrier-relaxation pattern in the $40^{\circ} \mathrm{C}$ and $50^{\circ} \mathrm{C}$ samples seems to have a similar trend, whereas the $25^{\circ} \mathrm{C}$ and $60^{\circ} \mathrm{C}$ samples found to have a slightly different pattern as compared to the previous two samples.

The results obtained at $900 \mathrm{~nm}$ were slightly different from the above. The probe pulse monitors the initially freely available electrons presented in the deep traps and then the trapped electrons populated there. This is because the CdSe nanostructured materials prepared by the $\mathrm{CD}$ method have a lot of defect states. As the energy of this probe photon is very less than that of the pump photons as well as that of the excitonic absorption peak position, so there was no bleach signal for this probe wavelength. The decay time constants obtained from kinetic profiles at this probe wavelength indicate the recombination time for the electrons and the holes at the trap centers as well as at the two band structures. The decay time constants match well with the absorption decay time constants obtained for other probe wavelengths. Similarly, there was a slight difference in the time constants obtained in the four different samples. This could be due to the fact that the change in the grain size of around $1 \mathrm{~nm}$ within the quantum confinement regime does not make any significant deviations in the photo-excited carrier relaxation processes among these four sets of samples. Hence, it is predicted that these kinds of materials could be useful for the devices based on a fast optical response.

\section{CONCLUSION}

The photo-excited carrier relaxation processes in cadmium selenide nanocrystal thin films prepared by chemical deposition method have been studied by nondegenerate femtosecond pump-probe spectroscopic method. The induced absorption followed by a fast bleach recovery within a less than 3-picosecond time scale indicates that the photo-excited electrons are first trapped by the trap sites and then the trapped electrons absorb the probe light to a higher-energy level in the conduction band which exhibits such a delayed absorption process. The short time constant, $<1$ picosecond, was attributed to the trapping of electrons by the surface and/or deep traps, and the long-time constant, $>100$ picoseconds, was due to the recombination of the trapped carriers. The amplitude of the bleach signal is very high as compared to that of the residual part of the induced absorption decay, which indicates that the carrier trapping process is a major phenomenon in these materials. The samples obtained at $40^{\circ} \mathrm{C}$ and $50^{\circ} \mathrm{C}$ were found to have similar carrier relaxation pattern which is different from the other two samples. 


\section{ACKNOWLEDGMENTS}

The authors would like to acknowledge Ms. Elena Pilina, Nanotec Electronica, Madrid, Spain, for her help in the AFM measurements. They also like to acknowledge Dr. S. K. Sarkar, Head of Radiation and Photochemistry Division for encouragement.

\section{REFERENCES}

[1] L. Han, D. Qin, X. Jiang, et al., "Synthesis of high quality zincblende CdSe nanocrystals and their application in hybrid solar cells," Nanotechnology, vol. 17, no. 18, pp. 4736-4742, 2006.

[2] R. E. Bailey, A. M. Smith, and S. Nie, "Quantum dots in biology and medicine," Physica E, vol. 25, no. 1, pp. 1-12, 2004.

[3] O. Niitsoo, S. K. Sarkar, C. Pejoux, S. Ruhle, D. Cahen, and G. Hodes, "Chemical bath deposited CdS/CdSe-sensitized porous $\mathrm{TiO}_{2}$ solar cells," Journal of Photochemistry and Photobiology A: Chemistry, vol. 181, no. 2-3, pp. 306-313, 2006.

[4] A. Nozik, "Quantum dot solar cells," Physica E, vol. 14, no. 1-2, pp. 115-120, 2002.

[5] I. Robel, V. Subramanian, M. Kuno, and P. V. Kamat, "Quantum dot solar cells. Harvesting light energy with CdSe nanocrystals molecularly linked to mesoscopic $\mathrm{TiO}_{2}$ films," Journal of the American Chemical Society, vol. 128, no. 7, pp. 2385-2393, 2006.

[6] K.-C. Chu, W.-S. Su, and Y.-F. Chen, "Liquid crystals driven by CdSe semiconductor," Journal of Applied Physics, vol. 100, Article ID 024516, 4 pages, 2006.

[7] S. K. J. Al-Ani, H. H. Mohammed, and E. M. N. Al-Fwade, "The optoelectronic properties of $\mathrm{CdSe}$ : $\mathrm{Cu}$ photoconductive detector," Renewable Energy, vol. 25, no. 4, pp. 585-590, 2002.

[8] Y. Araki, K. Ohkuno, T. Furukawa, and J. Saraie, "Green light emitting diodes with CdSe quantum dots," Journal of Crystal Growth, vol. 301-302, pp. 809-811, 2007.

[9] J. Qiu, H. Cheng, J. M. de Puydt, and M. A. Haase, "Recent developments in the MBE growth of wide bandgap IIVI semiconductors for laser diodes and LEDs," Journal of Crystal Growth, vol. 127, no. 1-4, pp. 279-286, 1993.

[10] S. S. Kale and C. D. Lokhande, "Thickness-dependent properties of chemically deposited CdSe thin films," Materials Chemistry and Physics, vol. 62, no. 2, pp. 103-108, 2000.

[11] R. B. Kale and C. D. Lokhande, "Systematic study on structural phase behavior of CdSe thin films," Journal of Physical Chemistry B, vol. 109, no. 43, pp. 20288-20294, 2005.

[12] C. D. Lokhande, E.-H. Lee, K.-D. Jung, and O.-S. Joo, "Ammonia-free chemical bath method for deposition of microcrystalline cadmium selenide films," Materials Chemistry and Physics, vol. 91, no. 1, pp. 200-204, 2005.

[13] S. Gorer and G. Hodes, "Quantum size effects in the study of chemical solution deposition mechanisms of semiconductor films," Journal of Physical Chemistry, vol. 98, no. 20, pp. 53385346, 1994.

[14] K. K. Mishra and K. Rajeshwar, "A re-examination of the mechanisms of electrodeposition of $\mathrm{CdX}$ and $\mathrm{ZnX}(\mathrm{X}=\mathrm{Se}, \mathrm{Te})$ semiconductors by the cyclic photovoltammetric technique," Journal of Electroanalytical Chemistry, vol. 273, no. 1-2, pp. 169-182, 1989.

[15] M. Ichimura, K. Takeuchi, A. Nakamura, and E. Arai, "Photochemical deposition of Se and CdSe films from aqueous solutions," Thin Solid Films, vol. 384, no. 2, pp. 157-159, 2001.
[16] Y. Yang, D. Z. Shan, J. Y. Zhang, et al., “The formation mechanism of self-assembled CdSe quantum dots," Journal of Crystal Growth, vol. 233, no. 4, pp. 785-790, 2001.

[17] D. Noda, T. Aoki, Y. Nakanishi, and Y. Hatanaka, "Epitaxial growth of CdSeTe films by remote plasma enhanced metal organic chemical vapor deposition," Vacuum, vol. 59, no. 2-3, pp. 701-707, 2000.

[18] L. Qu and X. Peng, "Control of photoluminescence properties of CdSe nanocrystals in growth," Journal of the American Chemical Society, vol. 124, no. 9, pp. 2049-2055, 2002.

[19] Z. A. Peng and X. Peng, "Nearly monodisperse and shapecontrolled CdSe nanocrystals via alternative routes: nucleation and growth," Journal of the American Chemical Society, vol. 124, no. 13, pp. 3343-3353, 2002.

[20] L. Manna, E. C. Scher, and A. P. Alivisatos, "Synthesis of soluble and processable rod-, arrow-, teardrop-, and tetrapodshaped CdSe nanocrystals," Journal of the American Chemical Society, vol. 122, no. 51, pp. 12700-12706, 2000.

[21] P. Maly, J. Kudma, F. Trojanek, et al., "Dominant role of surface states in photoexcited carrier dynamics in CdSe nanocrystalline films prepared by chemical deposition," Applied Physics Letters, vol. 77, no. 15, pp. 2352-2354, 2000.

[22] M. Simurda, P. Nemec, and J. Preclikova, "Ammonia effect on surface-mediated carrier dynamics in CdSe nanocrystals," Thin Solid Films, vol. 503, no. 1-2, pp. 64-68, 2006.

[23] X. Ai, R. Jin, C. Ge, et al., "Femtosecond investigation of charge carrier dynamics in CdSe nanocluster films," Journal of Chemical Physics, vol. 106, no. 108, pp. 3387-3392, 1997.

[24] Q. Darugar, C. Landes, S. Link, A. Schill, and M. A. El-Sayed, "Why is the thermalization of excited electrons in semiconductor nanoparticles so rapid? Studies on CdSe nanoparticles," Chemical Physics Letters, vol. 373, no. 3-4, pp. 284-291, 2003.

[25] V. I. Klimov, A. A. Mikhailovsky, D. W. McBranch, C. A. Leatherdale, and M. B. Bawendi, "Mechanisms for intraband energy relaxation in semiconductor quantum dots: the role of electron-hole interactions," Physical Review B, vol. 61, no. 20, pp. R13349-R13352, 2000.

[26] T. W. Roberti, N. J. Cherepy, and J. Z. Zhang, "Nature of the power-dependent ultrafast relaxation process of photoexcited charge carriers in II-VI semiconductor quantum dots: effects of particle size, surface, and electronic structure," Journal of Physical Chemistry, vol. 108, no. 5, pp. 2143-2151, 1998.

[27] C. Burda and M. A. El-Sayed, "High-density femtosecond transient absorption spectroscopy of semiconductor nanoparticles. A tool to investigate surface quality," Pure and Applied Chemistry, vol. 72, no. 1-2, pp. 165-177, 2000.

[28] H. Wang, C. M. Donega, A. Meijerink, and M. Glasbeek, "Ultrafast exciton dynamics in CdSe quantum dots studied from bleaching recovery and fluorescence transients," Journal of Physical Chemistry, vol. 110, no. 2, pp. 733-737, 2005.

[29] C. Burda, S. Link, T. C. Green, and M. A. El-Sayed, "Electron shuttling across the interface of CdSe nanoparticles monitored by femtosecond laser spectroscopy," Journal of Physical Chemistry, vol. 103, no. 11, pp. 1783-1788, 1999.

[30] G. Ramakrishna, A. K. Singh, D. K. Palit, and H. N. Ghosh, "Slow back electron transfer in surface-modified $\mathrm{TiO}_{2}$ nanoparticles sensitized by alizarin," Journal of Physical Chemistry B, vol. 108, no. 5, pp. 1701-1707, 2004.

[31] D. J. Norris and M. G. Bawendi, "Measurement and assignment of the size-dependent optical spectrum in CdSe quantum dots," Physical Review B, vol. 53, no. 24, pp. 16338-16346, 1996. 
[32] B. Alperson, I. Rubinstein, and G. Hodes, "Identification of surface states on individual CdSe quantum dots by roomtemperature conductance spectroscopy," Physical Review B, vol. 63, no. 8, Article ID 081303, 4 pages, 2001.

[33] S. Sapra and D. D. Sarma, "Evolution of the electronic structure with size in II-VI semiconductor nanocrystals," Physical Review B, vol. 69, Article ID 125304, 7 pages, 2004.

[34] R. B. Kale, S. D. Sartale, B. K. Chougale, and C. D. Lokhande, "Growth and characterization of nanocrystalline CdSe thin films deposited by the successive ionic layer adsorption and reaction method ," Semiconductor Science and Technology, vol. 19, pp. 980-986, 2004.

[35] C. Burda, S. Link, M. B. Mohamed, and M. El-Sayed, "The pump power dependence of the femtosecond relaxation of CdSe nanoparticles observed in the spectral range from visible to infrared," Journal of Chemical Physics, vol. 116, no. 9, pp. 3828-3833, 2002.

[36] S. D. Benjamin, H. S. Loka, A. Othonos, and P. W. E. Smith, "Ultrafast dynamics of nonlinear absorption in lowtemperature-grown GaAs," Applied Physics Letters, vol. 68, no. 18, pp. 2544-2546, 1996. 

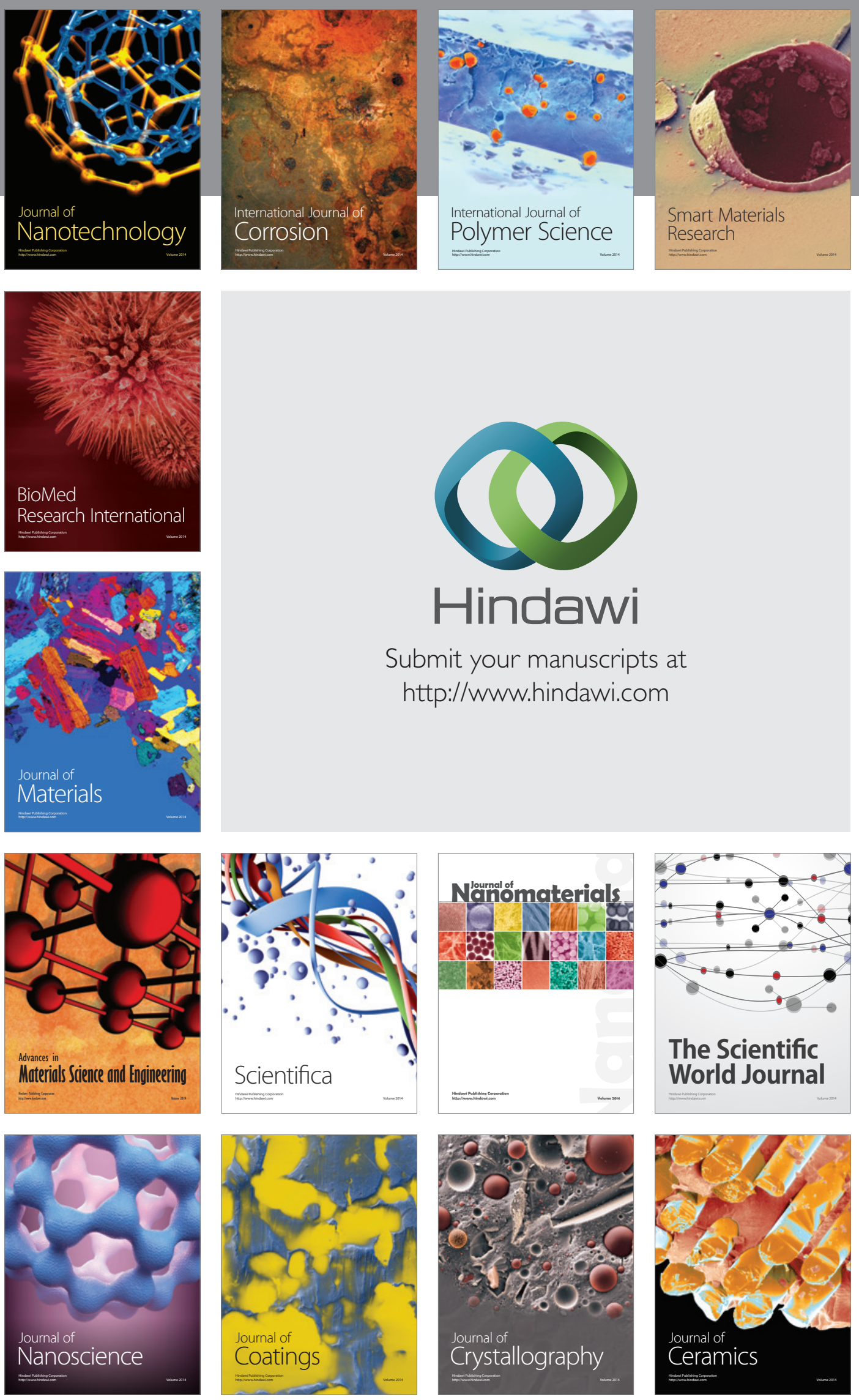

The Scientific World Journal

Submit your manuscripts at

http://www.hindawi.com

\section{World Journal}

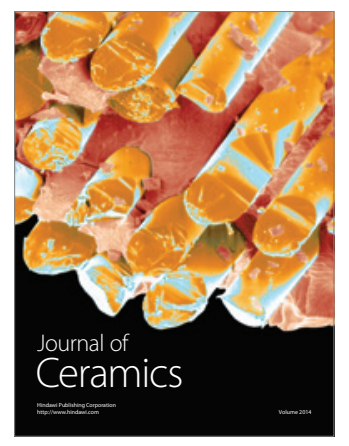

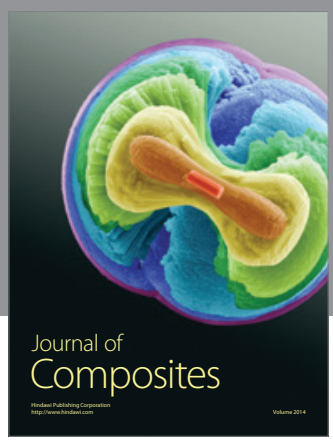
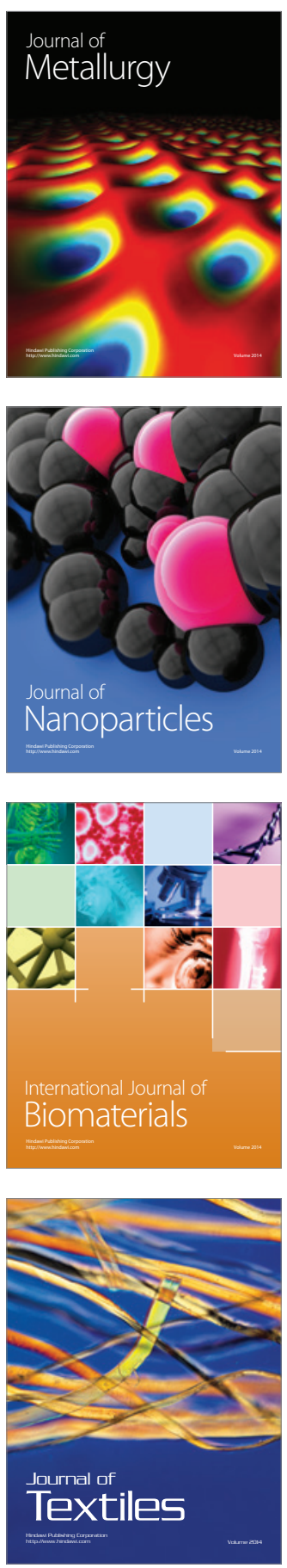